\title{
A Comparative Study of Integrated Thinking, Information Connectivity, and Value Creation Based on Integrated Reports of Japanese Companies
}

\author{
Kazunori Ito \\ Department of Accounting, School of Commerce, Senshu University, Tokyo, Japan \\ Email: itoh@isc.senshu-u.ac.jp
}

How to cite this paper: Ito, K. (2021). A Comparative Study of Integrated Thinking, Information Connectivity, and Value Creation Based on Integrated Reports of Japanese Companies. Journal of Human Resource and Sustainability Studies, 9, 413-433. https://doi.org/10.4236/jhrss.2021.93026

Received: August 2, 2021

Accepted: September 6, 2021

Published: September 9, 2021

Copyright $\odot 2021$ by author(s) and Scientific Research Publishing Inc. This work is licensed under the Creative Commons Attribution International License (CC BY 4.0).

http://creativecommons.org/licenses/by/4.0/

(c) (i) Open Access

\begin{abstract}
This study examines three requirement conformities based on Japan's excellent integrated reports to use stakeholder engagement for management: integrated thinking, value creation, and information connectivity. It aims to clarify how excellent corporate reports of Japanese companies address these three challenges. Further, I demonstrate that these three challenges can be easily addressed using a balanced scorecard (BSC). By introducing a BSC, synergy creation and portfolio management can be visualized and closely connected through strategic themes. In this study, as Japanese companies disclose the most integrated reports to the world, I consider how award-winning Japanese companies address the three issues. The three companies that have won the Outstanding Company Award thus far are Omron in 2017, MS \& AD in 2018, and NSK in 2019. However, despite having won grand prizes for their excellent integrated reports in Japan, none of them succeeded in visualizing the causal relationship between financial and non-financial information. We assume that visualizing the first type of information connectivity (i.e., the causality between financial and non-financial information) is a major issue. The findings of the study are as follows. First, for integrated thinking, MS \& AD was the only company that visualized synergy creation and portfolio management as corporate strategies. Omron made use of integrated thinking that emphasized portfolio management, whereas NSK was not explicit in creating synergies or portfolio management. Second, the excellent integrated reports of Japanese companies visualized implementing business strategies to address social issues. Third, after examining Japan's excellent integrated reports, information connectivity was not visualized. Thus, we suggest that value creation and controlling value damage should be separated to
\end{abstract}


visualize value creation on a strategic map. By visualizing the value creation process using the BSC when creating an integrated report, all three requirements can be satisfied.

\section{Keywords}

Integrated Thinking, Integrated Reports of Japanese Companies, Information Connectivity, Value Creation, Stakeholder Engagement

\section{Introduction}

When disclosing information in integrated reports, stakeholder engagement must be considered such that two functions that contribute to the decision-making of investors and stakeholders and utility for modifying management strategy can be realized (Ito, 2016, 2019). Thus, integrated reporting has two functions: disclosing information to stakeholders and information used by management. This study examines integrated reporting using the approach of management information utilization.

Dumay et al. (2017) pointed out several challenges to the framework of the International Integrated Reporting Council (IIRC, 2013), mentioned on information disclosure in integrated reports. For management's use of information, the issues presented by Dumay et al. (2017) can be summarized into three: integrated thinking, value creation, and information connectivity. It can be understood that integrated reports of Japanese companies are issued by many companies, accounting for one-quarter worldwide, and have gained significant interest ${ }^{1}$. It has also been pointed out that the global reputation of Japan's integrated reports is not quite high. Meanwhile, the World International Capital/Assets Initiative (WICI) Japan has established an award system in consideration of the improvement of the country's integrated reports. Under this system, the three companies that have been awarded the Grand Prize for Excellence to date are OMRON Corporation, MS \& AD Insurance Group, and NSK Ltd. In this study, we consider how these award-winning companies address the three issues raised by Dumay et al. (2017) in their integrated reports.

This paper aims to clarify how excellent corporate reports of Japanese companies address integrated thinking, value creation, and information connectivity. Further, we demonstrate that these three challenges can be largely accomplished with a balanced scorecard. The remainder of this paper is organized as follows. Section 2 clarifies the disclosure and use of information in integrated reporting. Section 3 identifies the three issues pointed out by Dumay et al. (2017). Section 4 clarifies the value creation process of Japan's excellent integrated reports. Section ${ }^{1}$ In response to interviews with the DHBS Editor-in-ChiefRyo Otsubo, Chairman Kon of WICI Japan pointed out that there were approximately 1600 companies preparing integrated reports worldwide in 2018, of which more than 400 were prepared by Japanese companies. This article appears in the July 29, 2019 "DHBS Original Article". It can be downloaded (2019/12/19) at: https://www.dhbr.net/articles/-/6032?page=3 
5 examines Japan's excellent integrated reports in terms of the three issues related to information disclosure. Finally, the findings of this study are summarized in Section 6.

\section{Information Disclosure and Use}

According to the IIRC Framework, "the primary purpose of an integrated report is to explain to providers of financial capital how an organization creates, preserves or erodes value over time" (IIRC, 2021: p. 5). From this definition, the IIRC Consultation Draft shows that the integrated report aims to disclose information to investors. Based on this statement, the IIRC Consultation Draft notes that integrated reports also benefit stakeholders. It can be understood that these reports disclose information not only to investors but also to stakeholders. Information disclosure to these stakeholders is illustrated in Figure 1 (a).

In the same IIRC Framework, it is also pointed out that an integrated report " $t$ is a concise communication about how an organization's strategy, governance, performance and prospects, in the context of its external environment, lead to the creation, preservation or erosion of value over the short, medium and long term" (IIRC, 2021). According to this definition, integrated reporting is a communication tool between companies and stakeholders. However, it should be understood that that communication includes not only one-way communication but also two-way dialogue. Through this interpretation, it is conceivable that, for stakeholder engagement, stakeholders use this information, and the same information can also be used by company management to modify their strategies. The relationship between this stakeholder engagement information and management's use of it for strategy modification is illustrated in Figure 1(b).

The benefits of stakeholder engagement information being available to management for strategy modification will be clarified. In an environment where a strategy is formulated at the top, and a site can implement the strategy formulated by the top management, the strategy need not be modified. However, in

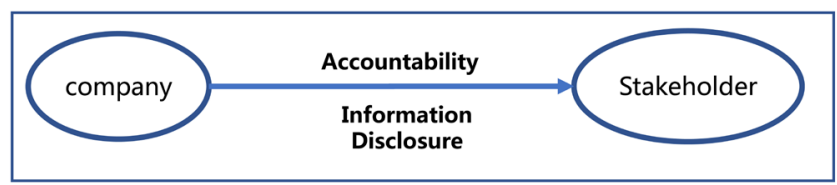

(a)

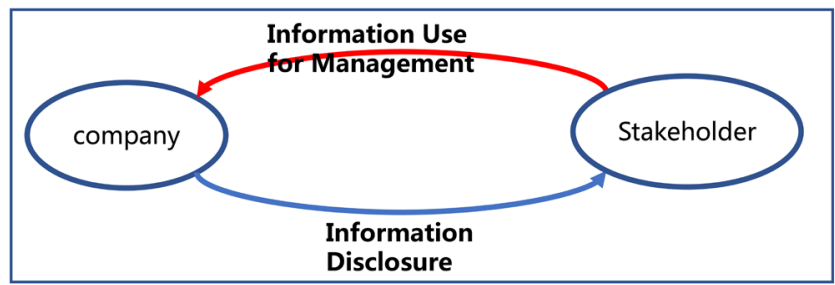

(b)

Figure 1. Information disclosure and information use: Source: created by the author. (a) Information Disclosure for Stakeholder; (b) Information Use for Management. 
today's rapidly changing environment, there is no guarantee that strategies formulated by the top management are correct. Therefore, even if a strategy formulated by the top management is visualized and communicated to the site, the site may fail to realize this strategy. To realize the strategy, it must be a modified or developed strategy. Thus, the introduction of a balanced scorecard (BSC) for the formulation and execution of strategies is highly effective (Kaplan \& Norton, 2004; Massingham et al., 2019). Companies that have introduced the BSC have made strategic revisions based on their financial and non-financial performance. However, nowadays, in the age of integrated reporting, incorporating engagement information from external stakeholders provides opportunities for the scorecard to be used in modifying and developing strategies. In summary, integrated reporting is an opportunity for management to use stakeholder engagement information in the current competitive environment.

\section{Challenges in the IIRC Framework}

In this section, I point out three issues, Dumay et al. (2017) criticized, as those related to management's use of information: integrated thinking, value creation, and information connectivity.

\subsection{Integrated Thinking}

The IIRC defines integrated thinking "is the active consideration by an organization of the relationships between its various operating and functional units and the capitals that the organization uses or affects" (IIRC, 2021: p. 3). It is also pointed out that the aim of integrated thinking is to "leads to integrated decisionmaking and actions that consider the creation, preservation or erosion of value over the short, medium and long term" (IIRC, 2021: p. 3). Dumay et al. (2017) criticized that because integrated thinking was only explained to this extent, its meaning could not be understood.

Integrated thinking can be understood from the perspective of strategy theory. Ito (2014) declared integrated thinking as an integrated management system. Here, an integrated management system is the effective implementation of a strategy by integrating previously separated management systems and tools for strategy formulation and implementation. The BSC is able to achieve this. Figure 2 shows an integrated management system based on the BSC.

As shown in Figure 2, the five steps are to 1) formulate a corporate strategy, 2) formulate a business strategy using a strategy map and a scorecard, 3) develop an operational plan by incorporating a business strategy into operations, 4) execute the strategy and operations, and 5) monitor and adapt the strategy and operations. In the integrated reporting age, the fact that the strategy and operations are modified using engagement information is a feature. The key to an integrated management system is to circulate these and rotate the PDCA (Plan, Do, Check, Action) cycle of strategy and operations. In other words, integrated thinking is to execute the strategy by integrating the formulation and execution 


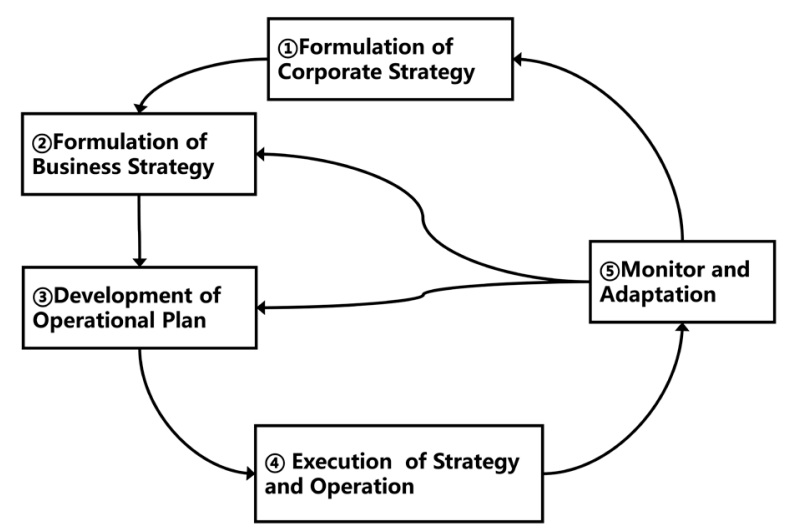

Figure 2. Integrated management system: source: Ito (2014).

of the strategy. An important part of this integrated thinking is the modification of the strategy. One information of this strategy modification is in the use of stakeholder engagement information.

In summary, integrated thinking involves visualizing the relationships within a company's organization, as well as its short, medium, and long-term balance. In other words, under a corporate strategy that considers integrated thinking, synergy creation and anergy suppression, as well as the short, medium, and long-term portfolio management, should be visualized. This corporate strategy also involves implementing corporate and business strategies, operating plans that incorporate them, and realizing strategies by modifying existing strategies and operational plans to adapt to the environment. The BSC, a management system for strategy formulation and implementation, is effective in realizing this integrated thought.

\subsection{Creating Value}

In the IIRC Framework (2013), the aim of integrated thinking was to create value. In this regard, Dumay et al. (2017) criticized that it was unclear whether value creation includes value damage. As mentioned earlier, in the IIRC Framework (2021), the aim of integrated thinking includes not only value creation but also maintenance and damage. Value maintenance is possible either as a result of value creation or controlling value damage. Therefore, integrated thinking consists of value creation and controlling of value damage when considered as management's activity.

Recently, sustainable development goals (SDGs) have become a hot topic in Japan. Although the core is the solution of social issues, it has both aspects of value creation and controlling value damage. Therefore, it is difficult to find the solution to social issues on a single strategic map. Consequently, separate strategic maps must be created for value creation and controlling value damage. Many of the integrated reports of Japanese companies visualize the value creation process to realize business strategies aimed at solving social issues. The value creation processes should be visualized separately for value creation and controlling value damage. The strategy must be visualized separately for value crea- 
tion and controlling value damage. This idea is illustrated in Figure 3.

As shown in Figure 3, corporate value is created from value creation and controlling value damage. Among these, value creation is created through management strategy. This management strategy is constructed by the business strategy of the business division and the corporate strategy of the headquarters. The business strategy of the business division is to earn profits from customers and is the main focus. The corporate strategy of the headquarters also includes portfolio management, but at its core is synergy creation.

Nevertheless, controlling value damage includes social contributions, such as environmental load and poverty alleviation, which are not related to the business. Indeed, to address social issues, product development that meets customer needs can be considered. However, if it concerns the business, then the business is the fundamental responsibility of a company and should be recognized as a strategy. SDGs featured at the United Nations Summit include innovation, which is both a social issue and a business-related concern and should be viewed as a strategy.

Solving social issues should be limited to measures for problems that are not related to the business. The focus is on social contributions such as no poverty and climate action. These are issues that companies cannot ignore, but not dealing with them could reduce corporate reputation and damage their value.

In summary, to visualize integrated reports in a strategic map, visualizing value creation and control of value damage, rather than visualizing business strategy and resolution of social issues, must be considered. It should also be noted that value creation must be regarded as directly related to the business and that what should be executed as a company, although not directly related to the business, must be regarded as controlling value damage.

\subsection{Information Connectivity}

Information connectivity refers to the connectivity between content elements and between content elements and capital. Content elements are all elements in the Octopus model shown in IIRC Framework (2021) that are closely related (see Figure 4). Among these content elements, the external environment, purpose, mission, vision, and governance are the environment and management policies surrounding other elements. Therefore, it is difficult to closely relate the abstract environment and management policy to specific business activities. Contrarily, it is relatively easy to clarify the connectivity of information for other elements. Therefore, we examine information connectivity for other elements.

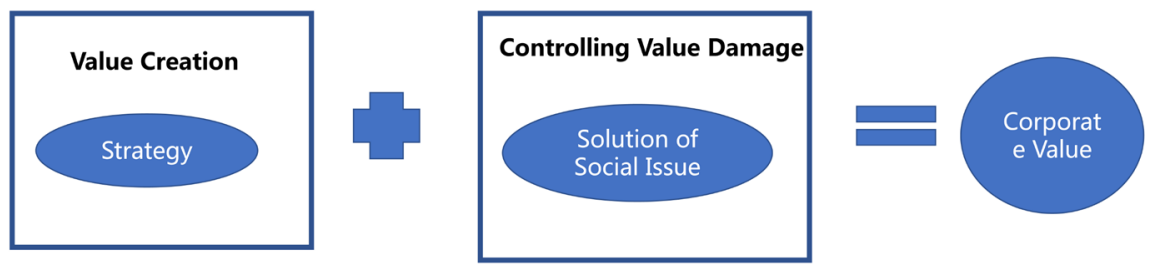

Figure 3. Creation of corporate value by value creation and value damage. 


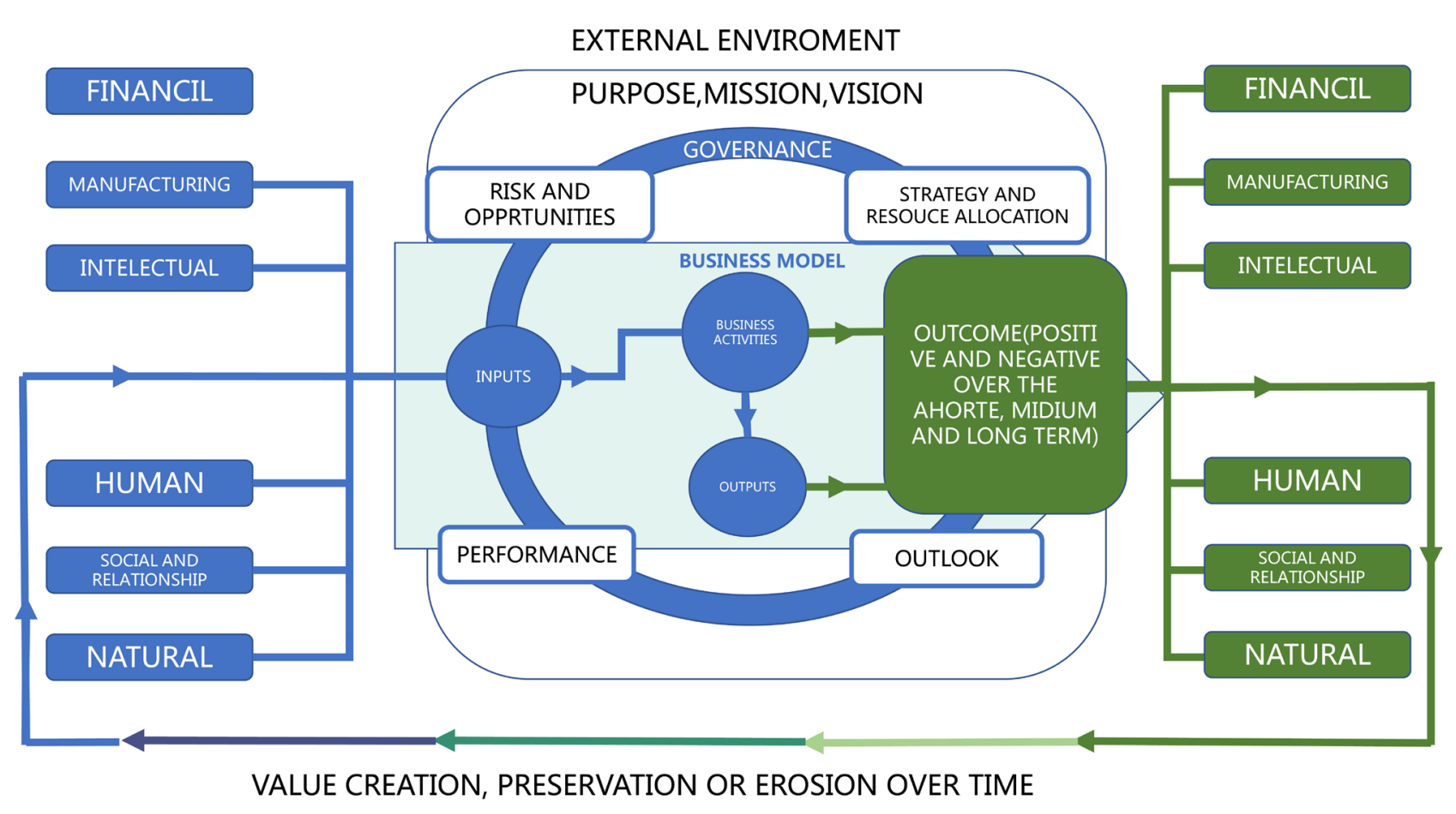

Figure 4. Octopus model of IIRC framework. Source: IIRC Framework (2021: p. 22).

The first type of information connectivity is to combine financial and non-financial information under a business model in close contact with business strategies and resource allocation formulated while considering risks and opportunities. It is called the connectivity of financial and non-financial information. The second type of information connectivity is the connectivity between the capital that created value and the capital that was input. It is called activity and capital connectivity. In visualizing the value creation process in the integrated report, the connectivity of these two pieces of information must be explicitly stated.

Can the Octopus model shown by the IIRC Consultation Draft visualize information connectivity? This point is, unfortunately, difficult. The Octopus model only illustrates the outline of what type of elements are there as content elements, but it does not illustrate the relationship between them. Therefore, another visualization that guarantees information connectivity is required. In this regard, the BSC strategic map can reveal the causal relationship between financial and non-financial information. In other words, by creating a strategy map, the first type of information connectivity can be secured. However, this alone cannot visualize the second type of information connectivity. Without measuring the intangible non-financial information, it cannot be linked to capital. Hence, further innovation is required.

\section{Integrated Report of Japanese Companies}

Japanese companies disclose the most integrated reports to the world. These reports are commended annually by WICI Japan. Thus far, three companies have won the Outstanding Company Award, which is given to the best report. The 
companies are Omron Co., Ltd. (hereinafter Omron) in 2017; MS \& AD International Assurance Holdings Co., Ltd. (hereinafter MS \& AD) in 2018; and NSK Ltd. (hereinafter NSK) in 2019. The main points of the integrated report prepared by these companies in 2020 are clarified below.

\subsection{Omron Integrated Report 2020}

Omron uses the SINIC (Seed-Innovation to Need-Impetus Cyclic Evolution) theory of its founder Kazuma Tateishi as a compass for management. In other words, they constructed the SINIC theory that predicts the future from the circular interrelationships of science, technology, and society based on the view that "(he) believed that solving social issues through business to create a better society required the ability to anticipate future social needs. He believed that a company needed a compass to help predict the future (Omron Corporation, 2020: p.1)". In other words, the corporate objective is to solve social issues. This SINIC theory is Omron's corporate philosophy.

According to a message from the company's CEO, "Omron has promoted selection and diversification based on its corporate philosophy (Omron Corporation, 2020: p. 12)". In other words, even if multiple businesses act autonomously under the corporate philosophy, they are incorporated into resilience through the ability to create synergies and business portfolios that incorporate diversity. It is doubtful that autonomous behavior can create synergies. However, there is no further explanation for the creation of synergies.

Meanwhile, the portfolio is illustrated in Figure 5. Omron's portfolio is divided into four areas according to return on invested capital (ROIC) and sales growth rate. ROIC and sales growth rates have thresholds of $10 \%$ and $5 \%$, respectively. It can be understood that such portfolio management is diversified for each business unit.

Omron's value creation process is shown in Figure 6. This process inputs five types of capital into the business creation process, outputs the results of business

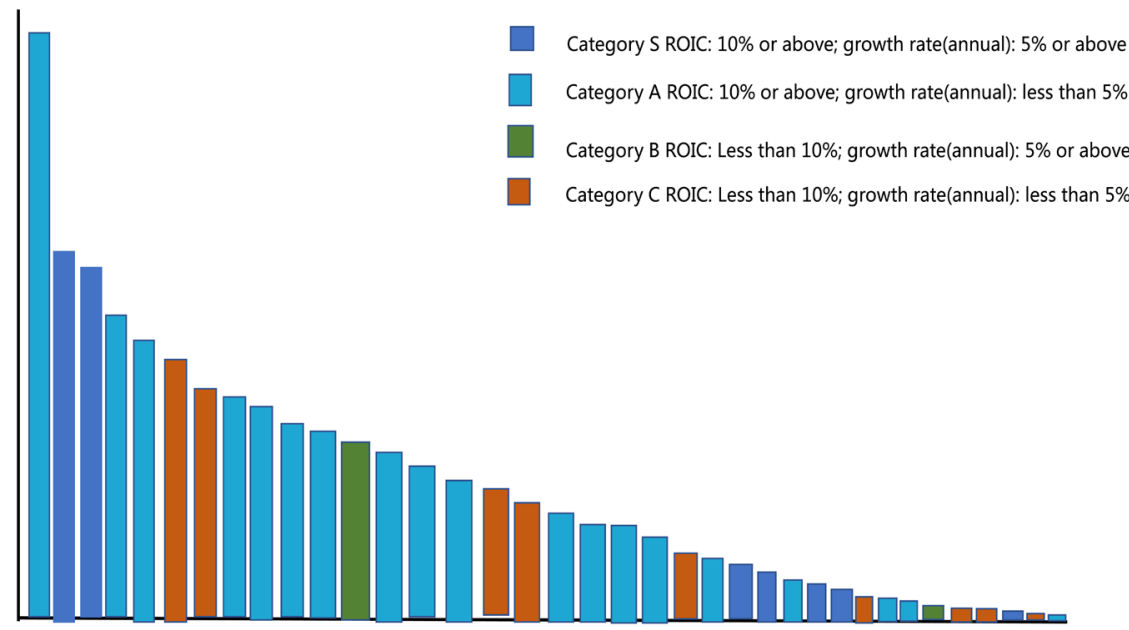

Figure 5. Business portfolio of Omron. Source: Omron (2020: p. 27). 


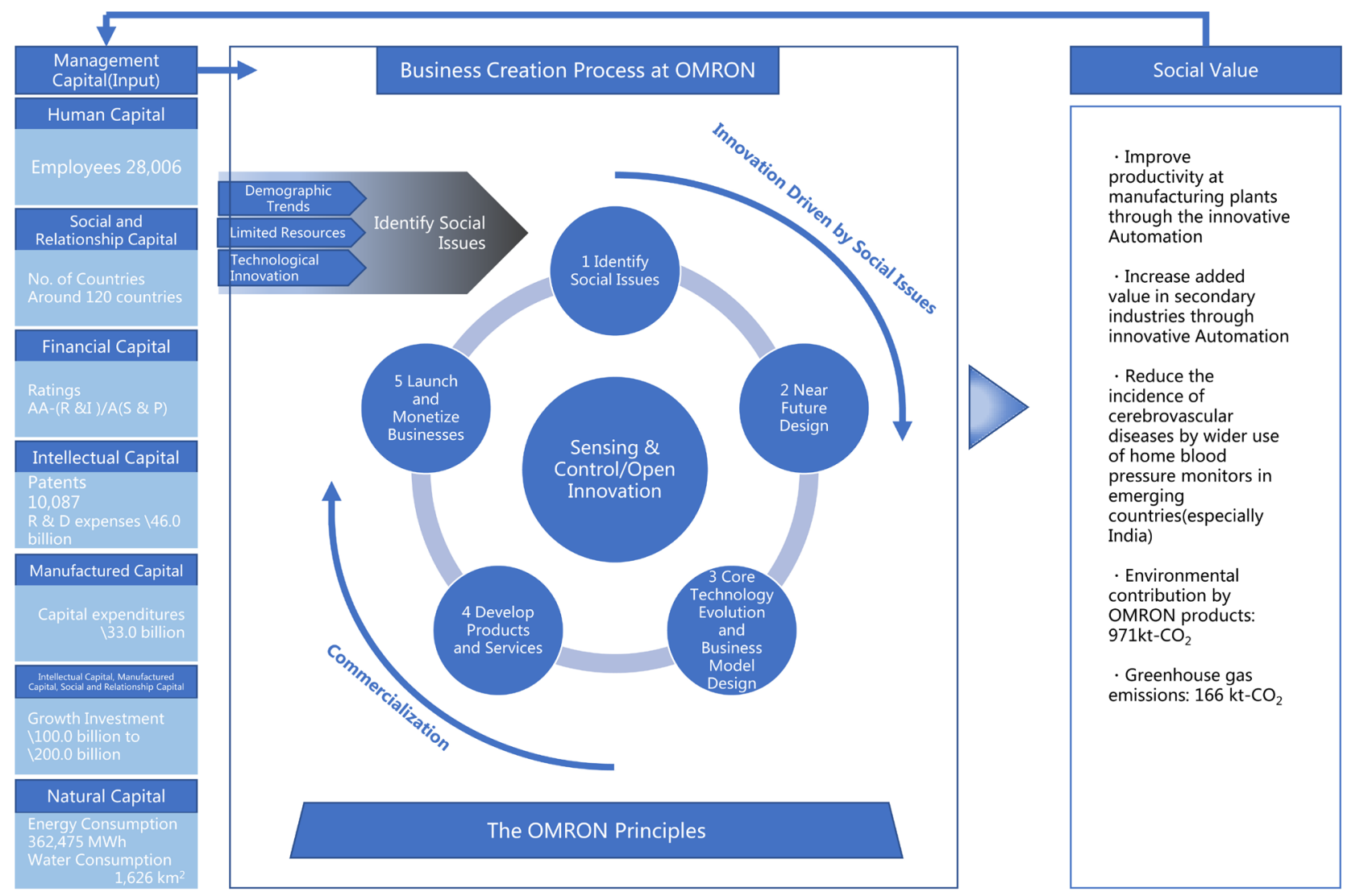

Figure 6. Value creation process of Omron. Source: Omron (2020: pp. 9-10).

activities, creates social value for each domain, and realizes goals related to the mid-term management plan and sustainability.

The value creation process in Figure 6 has issues with respect to value creation. As it advocates the SINIC theory, it is important to create social value, and it becomes a value creation process for solving social issues. Both the solution of social issues by business strategy and controlling value damage should be visualized.

In Figure 6, the business creation process involves the search for social issues (i.e., population growth, resource constraints, and technological innovation) and the design of the near future under the corporate philosophy. Based on this, it is a business process that serves as a bridge from the deepening of core technologies and the creation process of designing business models to the commercialization process that aims to launch and monetize the business by developing products and services. For each of the four domains (i.e., factory automation, healthcare, mobility, and energy management), social value is created through the output of products and services while aiming to realize the mid-term management plan and thus contributing to the realization of sustainability goals.

Omron's mid-term management plan (VG2.0) was started in 2017 as the final stage of its 10-year long-term vision (Omron, 2020). This mid-term management plan covers four years (see Figure 7). 


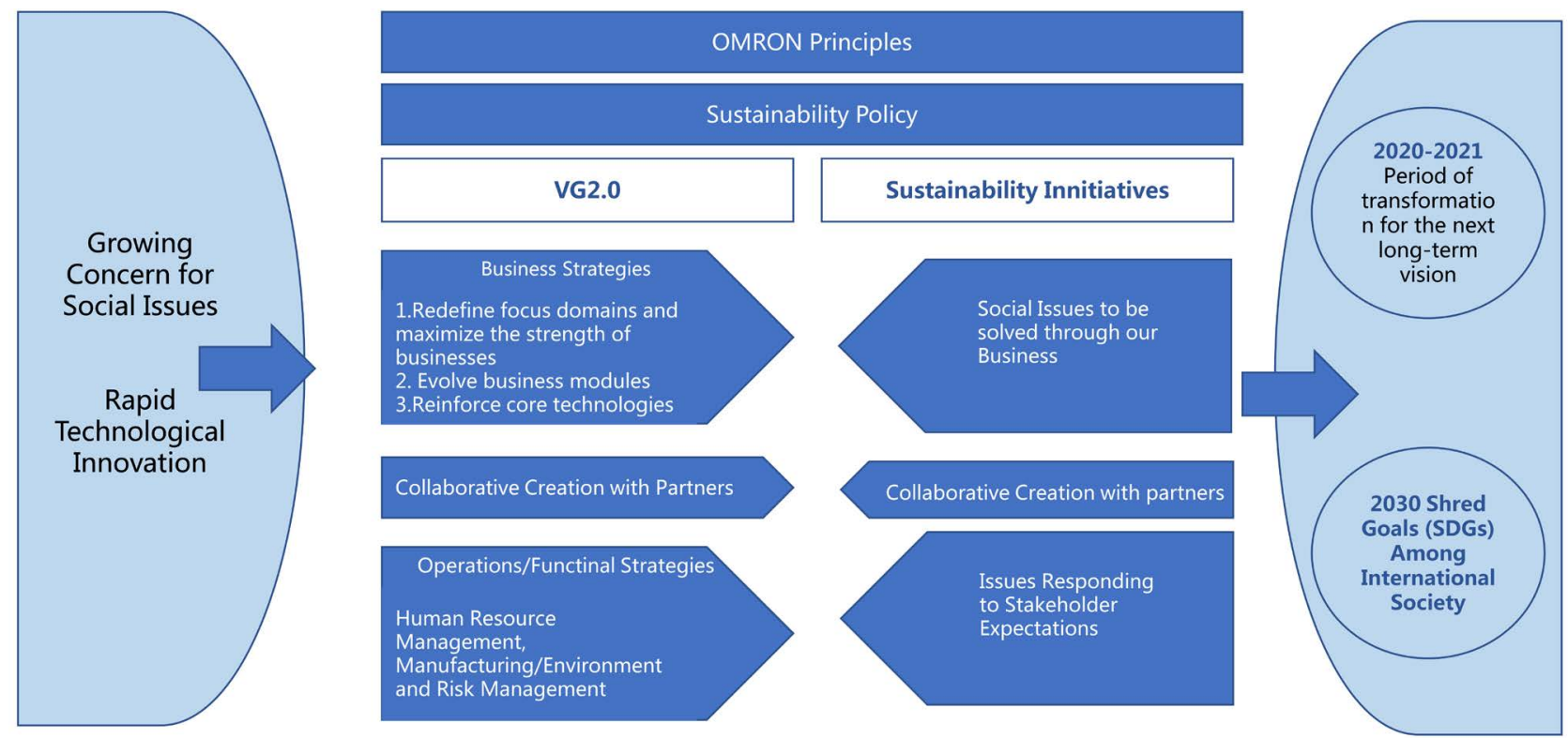

Figure 7. Mid-term management plan of Omron. Source: Omron (2020: pp. 29-30).

From Figure 7, to address social issues and rapid technological innovation, the following business strategies were formulated: 1) reset the focus domains and strengthen the business, 2) evolve the business model, and 3) strengthen core technologies. In addition to collaborating with partners, as a functional strategy, important sustainability issues are addressed by implementing human resource management, manufacturing, environment, and risk management. Important sustainability issues were social issues solved through the business, collaboration with partners, and meeting the expectations of stakeholders. These issues were not divided into value creation and controlling value damage. As a result, they were categorized as contributing to the achievement of SDGs over the super-long term while aiming to realize the mid-term management plan. No descriptions of materiality were found.

To address social issues, the value creation process goes one step further than corporate strategy and visualizes business strategy (Omron, 2020). By visualizing the business strategy, the relationship with the customer becomes clear. In addition, the purpose of value creation and controlling value damage to meet the expectations of stakeholders through business, including collaborative innovation with partners, is well-depicted. However, there was no distinction between value creation and controlling value damage.

The value creation process in Figure 6 did not visualize information connectivity. As the value creation process is an abstract conceptual diagram, creating a concrete visualization of information connectivity may have been difficult.

Omron's value creation process has several characteristics. First, for integrated thinking, portfolio management was the company's specialization, and they could not visualize the creation of synergies. Second, for value creation, the company aimed to achieve its mid-term plan and SDGs by solving social issues. Hence, it did not distinguish between value creation and controlling value dam- 
age. In addition, they handled manufacturing, environment, and risk management as matters related to both value creation and controlling value damage. Third, as an issue related to information connectivity, in the company's value creation process, the causal relationship between financial and non-financial information is unknown, and the first type of information connectivity has an issue. The relationship between activities and outcomes and capital is also unclear, and the second type of information connectivity has an issue.

\subsection{Integrated Report of MS \& AD}

MS \& AD's mission, vision, and values are shown on the back cover of the report. Their mission is to "contribute to the development of a vibrant society and help secure a sound future for the planet, by enabling safety and peace of mind through the global insurance and financial services business (MS \& AD, 2020, the back cover of the report)". Their vision is to "create a world-leading insurance and financial services group that consistently pursues sustainable growth and enhances corporate value (MS \& AD, 2020, the back cover of the report)". Their values are customer-first, integrity, teamwork, innovation, and professionalism.

The company has clarified three points as Stage 2 of Vision 2021: fully utilizing Group's strength, and portfolio. Figure 8 shows the ully utilizing Group's strength, which is related to synergy creation.

As shown in Figure 8, the company is using its strengths to leverage growth, strengthen profitability through group collaboration, and increase operational efficiency through standardization and collaboration. All of these are synergy creation. Growth aims to create synergy through joint product development. Strengthen profitability is coordinating the five business domains: domestic non-life

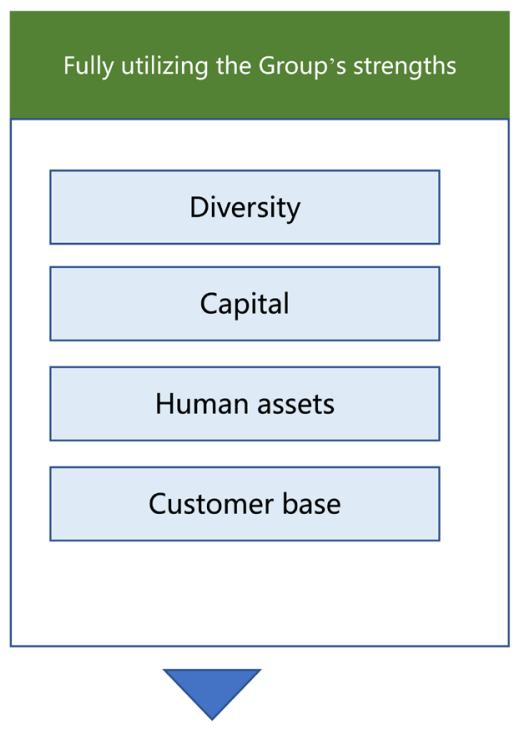

Growth(expanded top line)
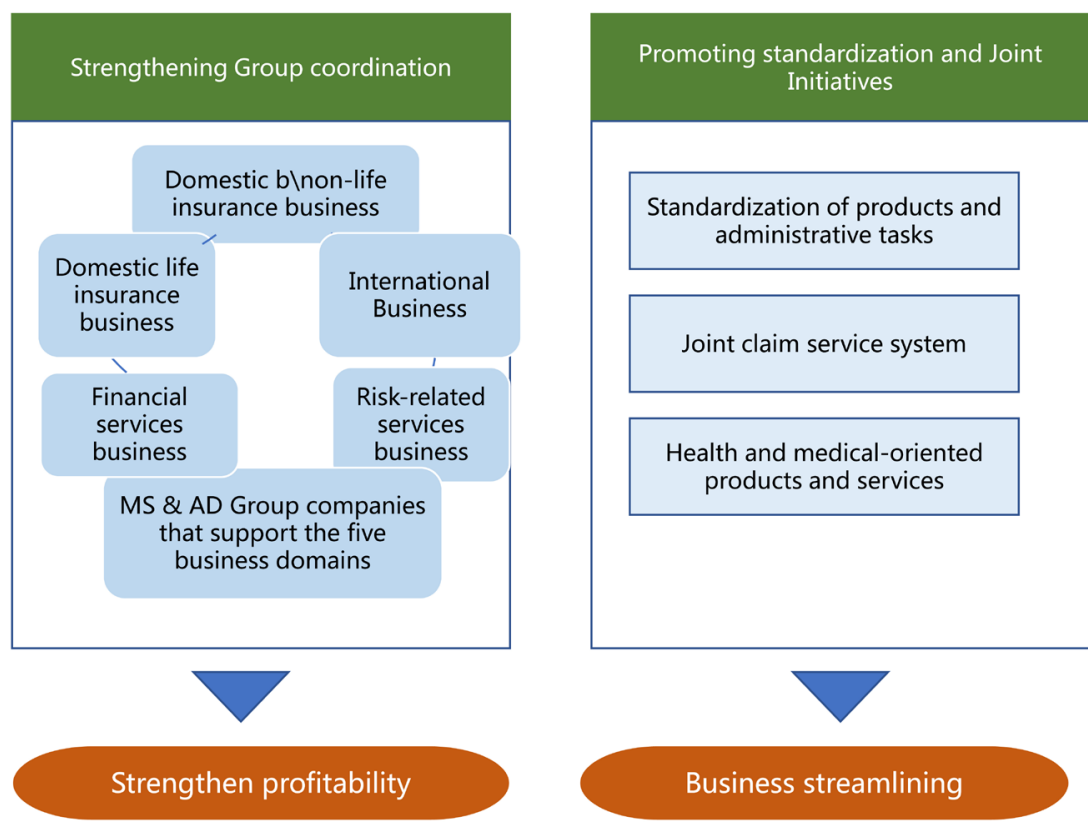

Figure 8. Synergy creation of MS \& AD. Source: MS \& AD (2020: p. 43). 
insurance business, domestic life insurance business, financial services business, international business, and risk-related services business. Business is streamlined through standardization and collaboration. Specific synergy creation is clarified in the domestic non-life insurance business in the segment growth strategy. As an example of joint development, "Observe and Protect Automobile Insurance (Dashcam type)" is illustrated as a jointly developed product by Mitsui Sumitomo Insurance and Aioi Nissay Dowa Insurance. This is a concrete example of the company's synergy creation.

The portfolio, on the other hand, is shown in Figure 9. The figure illustrates that the domestic non-life insurance business accounted for more than $50 \%$ in FY 2015. Let us compare this with the company's future goals. It can be observed that $50 \%$ of the company's future goals are in international business. Meanwhile, domestic non-life insurance business is estimated to increase 1.5 times from FY 2019 to 2021 , while the ratio will increasing from 54\% to 55\%. In addition, international business is estimated to increase 1.5 times from FY 2019 to 2021 while maintaining a ratio of $27 \%$.

MS \& AD's materiality is not simply a social issue but one that is considered together with the company's business. Seven materialities were extracted for each area of environment, social, and governance (ESG). These issues are as follows: 1 ) contribute to climate change mitigation and adaptation, 2) work toward the realization of "leaving no one behind", 3) strive for resilient development, 4) support "good health and longevity", 5) strive to improve the sustainability of natural capital, 6) create a comfortable mobility society without accidents, and 7) deal with new risks. Figure 10 shows the matrix of MS \& AD's long-term growth and contributions to social sustainability.

Figure 10 shows that the company's materiality map was similar to the materiality of social issues. It is a diagram that is elaborately devised by MS \& AD with reference to Global Sustainability Standards Board (GSSB, 2016).

Figure 11 shows MS \& AD's value creation process. It can be understood in the figure that five types of capital are formed as a result of inputting five types of capital into MS \& AD's business model and creating value in five business domains to address social issues. Here, MS \& AD's business model involves finding risks, reducing the economic burden when risks become reality, preventing the occurrence of risks, and minimizing the impact of risks. This value creation process differs in some respects from the IIRC Framework.

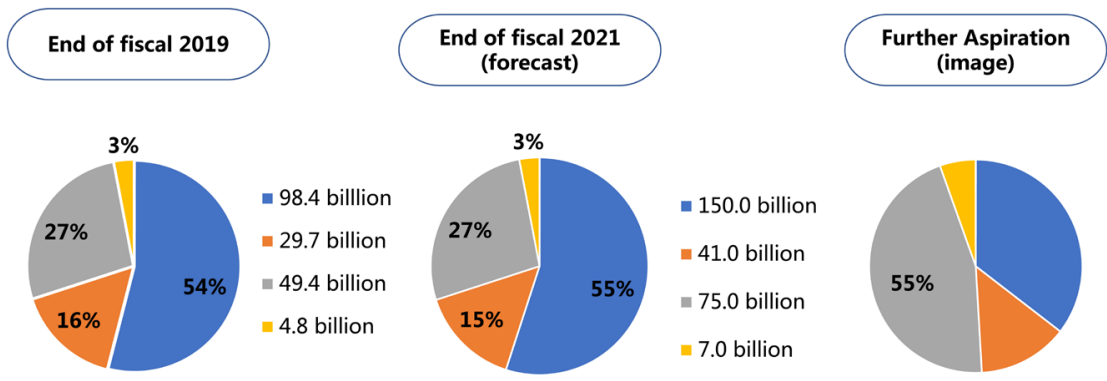

Figure 9. Portfolio of MS \& AD. Source: MS \& AD (2020: p. 43). 


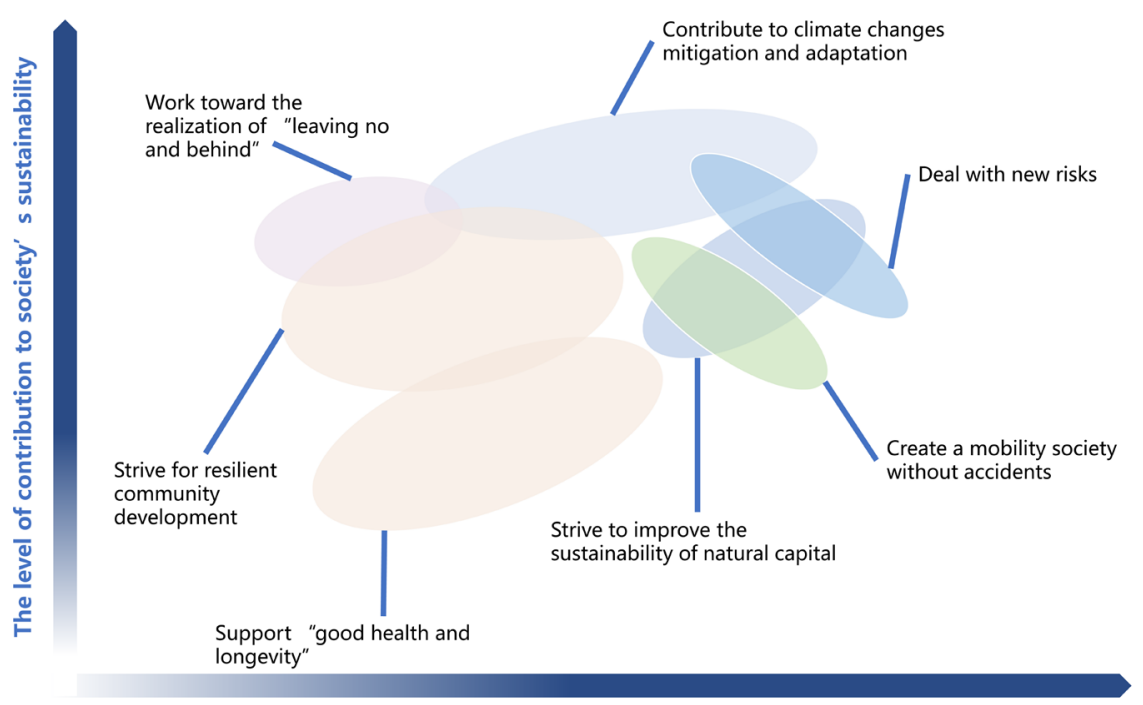

The level of impact on the long-term growth of the MS\&AD Insurance Group

Figure 10. Materiality of MS \& AD. Source: MS \& AD (2020: p. 39).

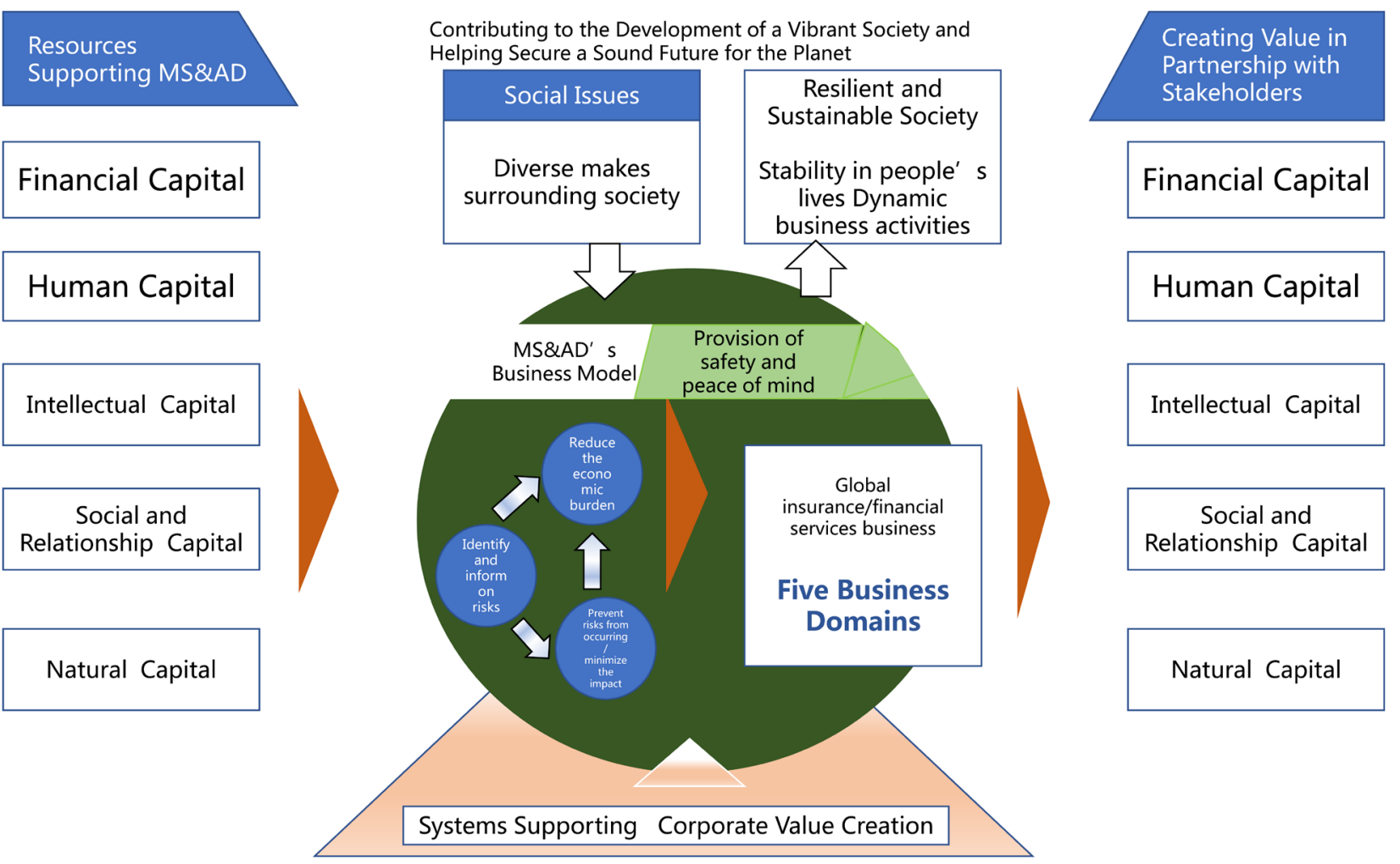

Figure 11. Value creation of MS \& AD. Source: MS \& AD (2020: pp. 14-15).

First, there is no distinction between value creation and controlling value damage. As the company envisions creating shared value (CSV) to address social issues through its business strategy, it does not visualize the control of value damage as a value creation process. CSV-related initiatives include cybersecurity measures for small- and medium-sized enterprises, development of telematics business in the US, support for the Nagano Prefectural SDGs Promotion Com- 
pany Registration System, provision of "Tontine Annuity" to prepare for longevity risks in anticipation of the arrival of the "100 Years of Life Era", efforts for early detection of open innovation dementia, efforts for the certification system of the Association for Business Innovation in Harmony with Nature and Community, and microinsurance to support micro-entrepreneurs in the Philippines. All of these are businesses that contribute to society. Not only do they solve social issues, but they also have economic benefits as business strategies. If only these are conducted, the issue is that activities to control value damage will no longer be proposed.

The value creation process in Figure 11 does not visualize the connectivity between financial and non-financial information. It is not completely ignored but reveals achievements as a financial and non-financial highlight. In terms of future outlook, the company has clarified its numerical financial targets as Vision 2021, which is its mid-term management plan. However, it does not show the type of relationship between these numbers. In summary, there is the issue of information connectivity.

MS \& AD's value creation process has several characteristics. First, for integrated thinking, synergy creation and portfolio management were well visualized. Second, for value creation, a business strategy was formulated to address social issues. Therefore, there was no distinction between value creation and controlling value damage. Third, for information connectivity, in the company's value creation process, there remains the issue that information connectivity is not visualized.

\subsection{NSK Report 2020}

NSK clarifies its corporate philosophy, management stance, action guidelines, and vision on the back cover of the NSK Report 2020. Their corporate philosophy is "NSK contributes to a safer, smoother and helps protect the global environment through its innovative technology integrating MOTION \& CONTROL 2 . As a truly international enterprise, we are working across national boundaries to improve relationships between people throughout the world". Their management stance is 1) to provide our customers with innovative and responsive solutions through our world leading technologies, 2) to provide challenges and opportunities to our employees, utilizing their skills and encouraging their creativity and individuality, 3) to identify the needs of the present and future, and to meet these needs by being flexible, agile, and dynamic, 4) to contribute to the communicates in which we operate, and 5) to manage our business from an international perspective and to develop a strong presence throughout the world. Their guiding principle of conduct is "Beyond Limits, Beyond Today". The NSK Vision 2026 is "Setting the Future in Motion".

NSK's president and CEO says that M\&A and open innovation should be emphasized for growth. To that end, he wants to establish an innovation center

${ }^{2}$ Motion \& Control is a corporate philosophy that expresses the concept of creating new movements for NSK, which has manufactured bearings. 
and seek M \& A and alliances with companies in Europe that have bearings, precision products, and condition monitoring technologies. Such growth strategies seem to envision the creation of synergies and portfolio management related to integrated thinking. However, as the CEO's comment does not describe a specific visualization, the company's corporate strategy is unknown with reference only to this comment.

Regarding corporate strategy, NSK is building a matrix organization of businesses and regions to support global management, as shown in Figure 12. The business is dispersed between the industrial machinery business and the automobile business, which seems to represent portfolio management. The region is divided into seven areas. Under this, they are trying to 1) reduce overlapping operations and costs under a policy of making shared Group-wide functions consistent and 2) speed up business execution responsiveness by entrusting decision-making to lower the organizations based on a broad framework decided by upper-tier organization. All of these are considered to be global management that seeks to create synergies.

In addition, under NSK Vision 2026, which is the company's vision for 2026, the company is formulating a business strategy with 3 key management tasks: business growth and profitability, utilization of robust managerial resources, and ESG management. In the industrial machinery business, the company is aiming for "respond to changes in the business environment and expand target field (NSK, 2020: p. 24)", and in the automobile business, the company is aiming to "reinforce the profit and establish a platform for the future growth (NSK, 2020: p. 24)".

NSK aims for creating shared value with stakeholders as a contribution to social issues under its corporate philosophy. This creating shared value is the goal of SGDs in 2030. Five activities have been stated as initiatives for SDGs. The first is to contribute to a safe and resilient social infrastructure through innovation. The second is to contribute to climate change countermeasures by reducing the

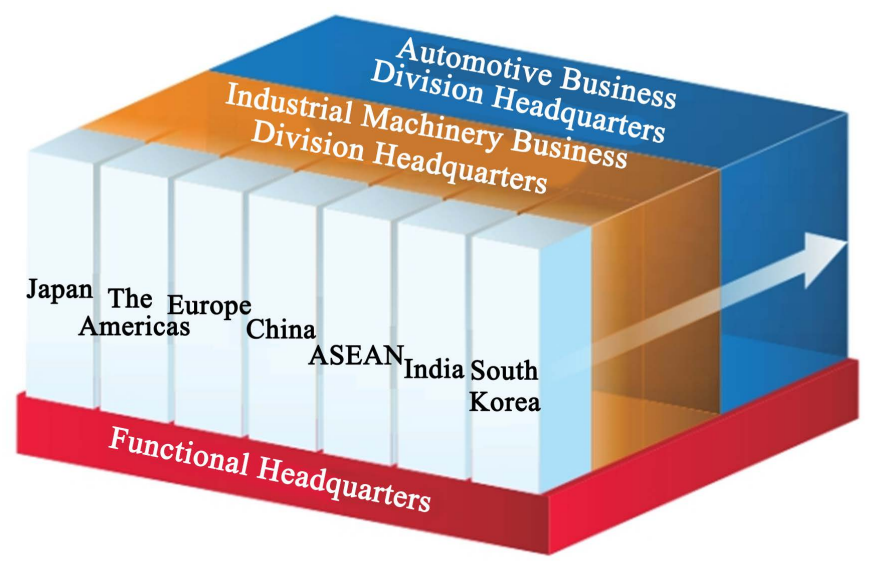

Note: Individual sites are divided by regions it has a presence in: Japan, The Americas Europe China ASEAN India and South Korea.

Figure 12. Global management of NSK. Source: NSK (2020: p. 44). 
impact of our business activities on the environment. The third is to contribute to the creation of a waste-free society and reduce impact on the global environment through environmentally friendly products and refuse resources. The fourth is to form richly diverse organizations where both employee motivation and value creation are fulfilled. Fifth is to enhance our dialogue through multi-stakeholder partnerships to increase the effectiveness of SDGs initiatives. It can be understood that the aim is the shared value of contributing to SDGs through such efforts.

NSK's value creation process has been clarified as a creating shared value model. Figure 13 shows this creating shared value model. The term creating shared value suggests that value is created not only with NSK but also with stakeholders such as customers.

Figure 13 shows that it is a model that contributes to create shared value with stakeholders by inputting capital under the mid-term management plan and achieving output and outcome targets through the business activities of the value chain. From Figure 13, it can be understood that the company does not distinguish between creating value and controlling value damage but is positioned as having a business strategy to address social issues. In addition, we did not find any descriptions of materiality.

Figure 13 also reveals the actual financial and non-financial information by the output and outcomes. However, the causal relationship between them is not clear. It is also unclear how business activities are linked to capital. Therefore, information connectivity, which is the relationship between content elements, is not visualized.

\section{Future Vision}

HSK Vision 2016

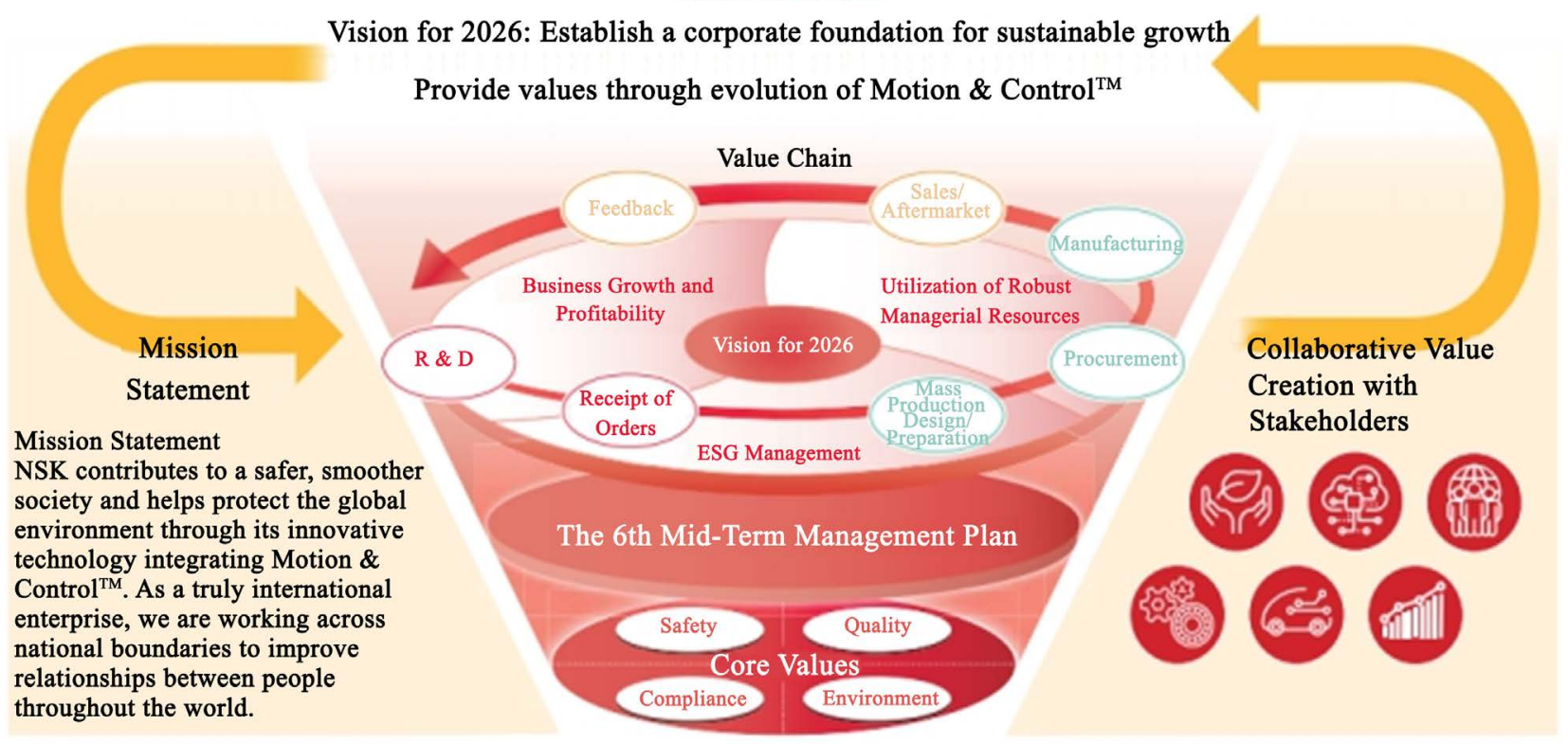

Figure 13. Collaborative value creation model of NSK. Source: NSK (2020: p.18). 
NSK's value creation process has several characteristics. First, for integrated thinking, synergy creation was visualized, but portfolio management was not always visualized. Second, for value creation, the company had formulated business strategies to solve social issues. As a result, there was no distinction between creating value and controlling value damage. Third, for information connectivity, in the company's value creation process, information connectivity is not visualized.

\section{Review of the Three Issues}

To ensure that management uses stakeholder engagement information, the disclosure of integrated reports needs to clarify integrated thinking, value creation, and information connectivity. To examine these three issues, I discussed the excellent integrated reports in Japan. These reports will once again be reviewed to clarify whether the three issues have been identified.

\subsection{Review of Integrated Thinking}

Let us consider Omron's integrated thinking. For disclosure of corporate strategy, there is synergy creation and portfolio management. Although it is pointed out that the company CEO is thinking of creating synergies, there is no description of specific synergies. Meanwhile, portfolio management is clarified in a message from the CFO. The entire company is divided into about 60 business units, and portfolio management is conducted using a matrix based on ROIC and sales growth rate. There are four categories according to the so-called Boston Consulting's Product Portfolio Management (PPM). In addition to Boston Consulting's PPM is based on product life cycle, the company names four areas to reflect product life cycle: new business entry, growth acceleration, restructuring, and divestiture. Figure 5 depicts the business units classified into these four areas in a downward sloping figure to the right in descending order of sales.

MS \& AD clarifies integrated thinking as Stage 2 of Vision 2021. This Priority Strategy 1 clarifies the creation of synergies. In other words, it is a growth strategy that aims for growth by fully utilizing the group's strengths, strengthening profitability by strengthening group coordination, and improving operational efficiency by promoting standardization and joint initiatives. In addition, Priority Strategy 3 discloses portfolio management. Specifically, the company aims to shift the group business, which was centered on domestic non-life insurance business, to international business. Currently, it is in the middle of the plan, and the forecast for FY 2021 is 55\% for domestic non-life insurance business, 15\% for domestic life insurance business, and $27 \%$ for international business.

NSK describes integrated thinking on global management as a global business foundation. The company is engaged in two businesses: the industrial machinery business and the automobile business. Regionally, it is a matrix-type organization in which the regional headquarters and functional headquarters support the business execution of the seven regions of Japan, the Americas, Europe, China, 
ASEAN, India, and South Korea. Although it seems intended for business and regional portfolios, there is no mention of portfolio management. This matrix organization reduces overlapping operations and costs under a policy of making shared Groupe-wide functions consistent and speed up business execution responsiveness by entrusting decision-making to lower the organizations based on a broad framework decided by upper-tier organizations. This part is thought to be intended to create synergy, but there is no clear description.

As previously mentioned, comparing the integrated thinking of the three companies reveals that OMRON emphasizes portfolio management, NSK emphasizes synergy creation, and MS \& AD emphasizes both portfolio management and synergy creation. In addition, while Omron uses PPM advocated by Boston Consulting to create a portfolio, MS \& AD assumed the business composition ratio as the ideal future and implemented portfolio management as a transition to that composition ratio. In addition, for synergy creation, MS \& AD explicitly stated synergy creation for growth, profit improvement, and operational efficiency. There was no clear description of synergy creation with Omron and NSK.

\subsection{Review of Value Creation}

Value creation should be separated into value creation and controlling value damage to visualize the strategy. However, in the IIRC, it was divided into value creation for the company and value creation for others, in addition to the explanation for value creation in the IIRC Framework. While value creation for the company can be achieved through business strategies, value creation for others is considered to be realized by solving social issues. However, business strategies and solving social issues are not independent, but rather business strategies were formulated to create value for the company and others by solving social issues. This concept is consistent with the creating shared value (CSV) of Porter and Kramer (2011).

CSV has the advantage of being able to simultaneously achieve economic and social value, but it is not intended to pursue only one of them. Therefore, even if economic value can be pursued through the development of new products that uncover potential needs that may or may not contribute to society, it will not be CSV. Moreover, social contribution that does not contribute to economic value is not CSV. The response differs depending on whether corporate value is perceived as CSV or stakeholder value. As this paper advocates stakeholder value, I believe that if stakeholders are satisfied with either economic or social value, then it should be the target.

Omron, MS \& AD, and NSK all advocate business strategies to address social issues. Their stance is that the role of a company is to simply address social issues. Companies that do not contribute to society are perceived as having no value. Responding to social needs under CSV may address social issues. However, it does not satisfy all stakeholders. Therefore, many Japanese companies may have introduced SDGs to disclose integrated reports. 
In relation to value creation, I compared the response to materiality. The result is that MS \& AD created its own map with reference to the matrix map of GSSB (2016) and selected seven social issues. Meanwhile, I did not find a description of materiality for Omron and NSK. Given that Omron regards everything related to the SINIC theory as materiality, its criteria for business selection is clear. However, the materiality of NSK was not clarified.

\subsection{Information Connectivity}

Information connectivity consists of two things: the causal relationship between content elements and the relationship between content elements and capital. It is difficult to clarify the causal relationship between the external environment, the risks and opportunities that are their responses, strategy and resource allocation, and performance and outlook. However, the cause-and-effect relationship between the former content elements (i.e., the combination of the first information) can be clarified as a story. Under this story, the causal relationship between the inputs, business activities, outputs, and outcomes associated with the business model needs to be clarified as a causal relationship between financial and non-financial information.

However, despite having won grand prizes for excellent integrated reports in Japan, none of them succeeded in visualizing the causal relationship between financial and non-financial information. Hence, it can be assumed that visualizing the first type of information connectivity (i.e., the causality between financial and non-financial information) is a major issue. This point can be resolved by visualizing the strategy map. If the causal relationship between financial and non-financial information can be visualized using a strategy map, it will be useful information not only for managers but also for stakeholders.

It is also useful for both managers and stakeholders to clarify the latter content elements and capital (the second type of information connectivity), specifically the relationship between activities and capital. However, non-financial information such as intangibles and natural capital is difficult to measure. In the excellent integrated reports, none of the companies address the second type of information connectivity. This is an issue that cannot be resolved simply by visualizing the strategy map. It is a complex issue that involves the measurement of intangibles.

\section{Conclusions}

This paper examined three requirements conformities based on Japan's excellent integrated reports to use stakeholder engagement for management: integrated thinking, value creation, and information connectivity. The three findings are as follows:

First, for integrated thinking, MS \& AD was the only company that visualized synergy creation and portfolio management as corporate strategies. Synergy creation and portfolio management were not connected even in MS \& AD. Further, 
this paper proposed that, by introducing the BSC, synergy creation and portfolio management can be visualized and closely connected through strategic themes. Omron had integrated thinking that emphasized portfolio management. In contrast, NSK was not explicit in either creating synergies or portfolio management.

Second, the excellent integrated reports of Japanese companies visualized the implementation of business strategies to address social issues. This sense of value is based on the CSV of Porter and Kramer (2011). Based on this sense of value, two issues should be addressed. 1) It is not permissible to pursue only economic value, nor is it permissible to pursue only social value. 2) There is a possibility that controlling value damage will not be viewed as an explicit problem anymore. This paper suggests that value creation and controlling value damage should be separated to visualize value creation on a strategic map. This separation makes it possible to distinguish between value creation and controlling value damage.

Third, after examining Japan's excellent integrated reports, information connectivity was not visualized. Developing a BSC strategic map allows the visualization of the connectivity of financial and non-financial information. However, building a strategy map does not make it possible to visualize the relationship between activities and capital.

By visualizing the value creation process using the BSC when developing an integrated report, all three requirements can be satisfied. However, only about 9\% of Japanese companies have introduced the BSC (Kawano, 2013; Kigyouyosan-Seido, 2018; Uehigashi, 2014). Therefore, the value creation process cannot be visualized with the BSC. Based on the results of Otomasa's survey (2003), the reasons why the implementation of the BSC in Japan has not progressed are as follows: 1) the convenience of performance indicators, 2) the existence of tradeoffs between performance indicators, 3) the existence of similar methods, 4) cost-benefits not being obtained, and 5) understanding of employees not being obtained. Despite the difficulties in implementing the BSC, there is more value in it. That is, if the value creation process by the BSC can be visualized, its greatest benefit is that information on stakeholder engagement can be used in management to modify the strategy. Thus, I would expect an increase in the number of companies that implement BSC.

\section{Acknowledgements}

We would like to thank Editage (www.editage.com) for their writing support on the Abstract. This work was supported by JSPS KAKENHI Grant Number JP21K01794.

\section{Conflicts of Interest}

The author declares no conflicts of interest regarding the publication of this paper.

\section{References}

Dumay, J., Bernardi, C., Guthrie, J., \& La Torre, M. (2017). Barriers to Implementing the 
International Integrated Reporting Framework: A Contemporary Accademic Perspective. Meditari Accounting Research, 25, 461-480.

https://doi.org/10.1108/MEDAR-05-2017-0150

GSSB (Global Sustainability Standards Board) (2016). GRI Standards. Global Sustainability Standards Board.

IIRC (International Integrated Reporting Council) (2013). The International $<I R>$ Framework. International Integrated Reporting Council.

IIRC (International Integrated Reporting Council) (2021). International $\langle I R>$ Framework. International Integrated Reporting Council.

Ito, K. (2014). BSC niyoru Senryaku no Sakutei to Jikkou-Jireidemiru Intangiburuse no Managiment to Tougou-Houkoku heno Kanrikaikei no Kouken. Doubunkan-Shyppan.

Ito, K. (2016). From Interest adjustment by Interested Parties to Engagement with Stake holders. Disclosure News, 32, 123-128.

Ito, K. (2019). Survey on Value Creation Process on Integrated Reporting. Kaikei, 196, 202-215.

Kaplan, R. S., \& Norton, D. P. (2004). Strategy Maps. Converting Intangible Assets into Tangible Outcomes. Harvard Business School Press.

Kawano, K. (2013). The Present Situation and Problems of the Management Accounting and the Cost Accounting of the Japanese Companies. The Study of Busines and Industry, No. 30, 56-86.

Kigyouyosan-Seido, K. (2018). Nihon Kigyou No Yosankanri No Jittai (pp. 193-207). Cyuou Keizaisya.

Massingham, R., Massingham, P. R., \& Dumay, J. (2019). Improving Integrated Reporting: A New Learning and Growth Perspective for the balanced Scorecard. Journal of Intellectual Capital, 20, 60-82. https://doi.org/10.1108/JIC-06-2018-0095

MS \& AD Insurerance Group Holdings (2020). MS \& AD Integrated Report.

NSK, Ltd. (2020). NSK Report 2020.

Omron, Ltd. (2020). Omron Integrated Report 2020.

Otomasa, S. (2003). Research on How to Use Performance Indicators in Japanese Companies: Comparison with Balanced Scorecard. The Rokkoudai Ronsyu, Keieigaku-Hen, 49, 29-54.

Porter, M. E., \& Kramer, M. R. (2011). Created Shared Value. Harvard Business Review, $89,52-77$.

Uehigashi, M (2014). The Current Conditions and Prospects of Management Accounting Practices in Japanese Non-Manufacturing Industries. Departmental Bulletin Paper, 60, 73-112. 